\title{
Intellectual property protection for scholarly publishing in the Italian framework: a globally open approach for medical and life sciences authors
}

\author{
Valentina Bozzato, ${ }^{1}$ Marianna Gnoato, ${ }^{1}$ Antonia Vilia, ${ }^{2}$ Mauro Apostolico ${ }^{2}$ \\ ${ }^{1}$ Istituto Oncologico Veneto IOV, IRCCS, Padova; ${ }^{2}$ University Library Services, University of Padova, Italy
}

\begin{abstract}
This paper aims at analyzing the importance of protection of intellectual property (IP) in biomedical scholarly publications, both for the author's reputation and the dissemination of scientific knowledge. The laws that regulate IP are very complex and differ from country to country. We shall focus on the Italian framework though many considerations could be applied to foreign contexts. IP is very articulated, yet often ignored, that is worth paying attention to a correct copyright management can help researchers promote their Work and the community to benefit from it. In the scholarly publishing field, there are two main areas: traditional publishers and open-access publishers. The first group requires a fee to access the content they publish and usually ask the authors for a complete transfer of copyright. The possibility to negotiate terms with such publishers is often overlooked: scholarly authors tend to think they do not have leverage in the publishing cycle. The so-called addendum and professional figures, like librarians and attorneys, can help manage the authors' intellectual property. On the other hand, open-access publishers give free access to published material, guaranteeing the protection of IP: thanks to the Creative Commons Licenses, the authors do not have to surrender their copyright to the publisher and can manage and control the use made out of their Work. Applying the principles put forth in this article implies enhancing research dissemination by increasing its impact and visibility. However, to achieve such a goal, it is necessary to protect intellectual property for the sake of authors, users, and scientific progress.
\end{abstract}

\section{Copyright between moral and economic aspects: the protection of intellectual property}

The Copyright legislation's objective is to regulate the relationship between the creator of the Work and the

Correspondence: Mauro Apostolico, University Library Services, University of Padova, Via Beato Pellegrino 28, 35137 Padova, Italy.

Tel.: +390498279718.

E-mail: mauro.apostolico@unipd.it

Key words: Copyright; publishing; creative commons licenses; intellectual property; open access; author agreements.

Acknowledgments: we would like to thank Christina Ann Drace for her linguistic revision.

Data availability statement: all data are available in the manuscript.

Conflict of interests: the authors declare no potential conflict of interests.

Received for publication: 4 February 2021.

Accepted for publication: 4 February 2021.

This work is licensed under a Creative Commons Attribution NonCommercial 4.0 License (CC BY-NC 4.0).

${ }^{\circ}$ Copyright: the Author(s), 2021

Licensee PAGEPress, Italy

Italian Journal of Medicine 2021; 15:77-84

doi:10.4081/itjm.2021.1473 subjects that will distribute it (publishers, distributors, producers). It seeks, together with the Patent legislation, to protect the intellectual property of the author.

Scholarly publications are regulated by Author's Rights legislation, which is divided into two main areas, aimed at protecting different aspects of the Work: the moral rights of the inventor/author and economic rights.

The so-called moral rights are inalienable and perpetual. They belong to the author/inventor, even after his/her death. Moral rights include the right of authorship, the right of unpublished work, the right of repentance, the right to the integrity of the work.

Economic rights represent the remunerative exploitation of the Work: they are used to obtain an income from their management. Economic rights include the right of republishing, transcribing, reproducing, distributing, and translating the Work. Differently from moral rights, economic rights are transferable to third parties: it means that the author transfers to a third party (for instance, to the publisher) the right to detain the economic income coming from the Work. If the transfer of the economic rights is not mindful and correctly managed, the author runs the risk of losing important rights over his/her Work. For authors who are about to publish with an Italian scholarly publisher, it is important to consider that the Italian Law explicitly provides that economic rights are independent of each other: authors can retain some 
self-archiving rights by providing for them an editorial agreement.

This article will explain how to manage economic rights in scholarly publications with the purpose of giving researchers several tools which might be helpful to protect the intellectual property of their Work.

The copyright framework brings in itself some important aspects of intellectual property:

- The rights belong to the Author: both the moral and the economic. The latter can be transferred, but at the very beginning they belong to the author. $\mathrm{He} / \mathrm{she}$ has to ponder how and what rights could be transferred to a third party.

- The Author might manage his/her rights in different ways: i) transferring all of the economic rights or just some of them; ii) assigning the rights to different subjects (some rights could be transferred to the publisher, some others to the institution where the author carried out the research); iii) transferring the rights in an exclusive or non-exclusive way.

- The transfer of rights occurs when the author and the publisher sign a contract.

- The rights - instead of being transferred - might be granted or licensed, to a third party through a user license.

\section{The Publishing contract, or so-called Copyright transfer agreement}

The Copyright transfer agreement is a document signed by the creator of the Work and the publisher. Through this document, the traditional publishers demand the authors' copyright transfer. This kind of contract is standard for scientific and academic publishers who require a paid subscription or a fee to give access to the content they publish. After signing a contract, the author transfers to the publisher all, or some, of the economic rights he/she previously owned in exchange for compensation or for free. Authors of scholarly publications will probably agree on saying that they hardly get paid for their articles. According to the journal's needs, publishers customize their own Copyright transfer agreement, listing different clauses (publishers that own more than one journal may contemplate different contracts for each journal). In the contract, scholarly publishers often demand the complete transfer of the authors' economic rights; usually, the document reports the following sentence: the undersigned authors transfer all copyright ownership in and relating to the Work, in all forms and media, to the Proprietor in the event that the Work is published (see, for example: https://www.elsevier.com/_data/promis_misc/asjsur_ ctaa.pdf).

What does the undersigning of this document involve? What are contractual obligations implied in the contract? Sometimes, signing this agreement does not allow the author to reuse his/her own Work in the fu- ture or have the scientific community's potential visibility. The complete transfer of the economic rights to the publisher might not allow the author to: i) distribute copies of the article to students and colleagues for teaching and/or research purposes; ii) archive the article on his/her own webpage or the institute's webpage or, the best solution, in an institutional or disciplinary repository; iii) publish the same Work in different document types, such as collections, essays, anthologies, conferences.

In worse cases, if the author signs the copyright agreement, he/she transfers all his/her own economic rights to the publisher. In case the author wants to use his/her own Work in the previously mentioned ways (share, archive, re-publish), he/she will have to ask the publisher permission to reuse, which is usually granted after payment of a fee.

However, publishers may have different clauses, more or less restrictive, in their contracts. The most restrictive agreements require the complete and exclusive transfer of economic rights. It means that the publisher will be the only one allowed to exploit and use all of them. Of course, some contracts imply fewer restrictions and give the author much more freedom to disseminate his/her own Work. Less restrictive contracts allow the author to share the Work with colleagues and students for teaching and research purposes, (self) archive it in a thematic repository such as Zenodo (https://zenodo.org/), arXiv (http://arxiv.org/), medrxiv (https://www.medrxiv.org/), biorXiv (https://www. biorxiv.org/), and many more, or institutional repository and republish his/her Work in collections, essays, anthologies, and so forth.

\section{Archiving rights}

As previously written, sometimes the author can archive his/her own Work in a repository. Even this practice is different according to the journal: the publisher can allow the author to archive one or more versions of the Work: preprint, postprint, publisher version, and can also establish an embargo period.

The preprint version is the draft article submitted to the journal. It is usually a double-spaced .doc file with minimal formatting. An article in preprint status has not yet been through the peer review process. The postprint version is the final draft of the article, accepted for publication, containing all the corrections required by the reviewers. The postprint version does not have the final publisher layout, and it is still a double-spaced doc file containing all the information that will be found in the final version. A .pdf file of the article represents the publisher version according to the publisher's layout (comprehensive of logos, the division into columns, graphics, and tables). It is the article that will be found on the journal's website.

The Copyright transfer agreement mentions if and 
how it is possible to archive the paper. If the publisher allows the author to archive his/her Work, it always specifies which version can be archived: preprint, postprint, publisher version. Sometimes the publisher may set an embargo: a period usually ranging from 6 to 12 months in science, technology and medicine (STM) disciplines during which self-archiving of the article is restricted: after this period, the access will be automatically open by the repository where the article was previously stored. The publisher can even decide to forbid the archiving of any version. The main funding bodies, including the EU, accept a maximum embargo period of 6 months.

An excellent tool to verify if and under what conditions it is possible to archive one's Work in a repository is Sherpa Romeo (https://v2.sherpa.ac.uk/romeo/), an online tool provided by Jisc (https://www.jisc.ac.uk/), which gives information about copyright and selfarchiving policies of academic journals. Sherpa Romeo API also provides a complete integration of the tool in Research institutions' Current Research Information Systems (CRIS) deposit workflows.

\section{Copyright transfer agreement timing}

'Should copyright be transferred before a manuscript is accepted?'. This is the title of an interesting perspective article by JA Teixeira Da Silva of 2017. ${ }^{1}$ The author analyzes the timing of copyright transfer agreements in submissions. He underlines that nowadays, there are journals that request the author to sign the agreement before peer review and editorial processing. He stresses the ethical consequences of this request because it may violate the author's rights. What if, after signing the so-called contract, the journal rejects the article? Does the publisher hold the economic rights, or are they back to the author? They return to the author. ${ }^{2}$ The contract must specify that if the journal accepts to publish the Work, then the rights are held by the publisher.

Clinicians or researchers who are publishing their works with an Italian scholarly publisher must take into account that, in the Italian copyright legal framework, the rights of economic exploitation are independent of each other: it is not strictly necessary to assign all the rights to the publishers. The Italian copyright law protects scholarly authors and their capability to retain some rights in front of the publication of their work (journal article, book chapter or monograph, etc.).

\section{Research: what role do scholarly journals play?}

Through publishing contracts, publishers can acquire most of the economic rights, which the authors should retain. Unfortunately, authors too often underestimate the Copyright transfer agreement clauses. However, why do publishers demand the transfer of all the rights from the author? And what role do scholarly journals have in the research field? Some debate on this topic was published in The Scholarly Kitchen blog in 2019:3 'Do journals fund research? No, they don't. Do journals pay royalties to authors? No, they don't. Do journals pay the peer reviewers who evaluate the quality of submissions? No, they don't. Do journals pay the academic editors who manage the process? Usually, they do not. In rare circumstances, journals may provide copyediting... I have never experienced that luxury, however. Then why do journals receive an exclusive right to sell access?

The legal answer is that the authors transfer copyright. The social answer is that authors prefer to publish in prestigious journals, whose toll access status is not causal but simply vestigial. The ethical answer does not exist. The rights to scholarship should be dedicated to society at large.'

Why do publishers ask authors to transfer their full economic rights, often in an exclusive way? Do publishers really need all the economic rights of the Work? Scholarly journals indeed represent a launch pad for research: publishing in top journals guarantees visibility because most of these journals are part of institutional library subscriptions (this might turn out not to be true: in 2018-2019, an increasing number of universities are ending their large deals with publishers). ${ }^{4}$ Then, for each manuscript, the publisher applies many steps: selecting publishable/worth publishing material, copyediting, formatting, typesetting, metadatation, harvesting, providing persistence to the document. These activities deserve to be recognized and rewarded. What is the author's role? Who does generate knowledge? What does the publisher's role matter if no one produces the intellectual raw material known as knowledge? Who holds the bargaining power between author and publisher? In the traditional publishing field, the publisher plays the lion's share. Researchers very often underestimate the consequences of giving away all their copyright. They feel encouraged to underwrite contracts in exchange for the so-called prestige that comes from publishing an article in top journals, which usually guarantees dissemination to a broad and influential audience. No researcher would have any doubts about surrendering all his/her copyrights to have an article published in a journal with a high Impact Factor. We could compare the relationship author-publisher to any commercial relationship: it is usually the subject holding the most significant bargaining power which dictates the rules. The same goes for someone applying for a loan: if we go to the bank and apply for a mortgage, the bank (the subject holding the capital) will decide whether or not to grant the mortgage or not. In the relationship author-editor, who holds the capital, in this case, the intellectual capital, is the creator. Unfortunately, it is too 
often forgotten in the publishing field that the bargaining power should be of those who created the intellectual raw material, the intellectual capital. What can a publisher do without the inventor of this knowledge?

\section{A keyword in scholarly publishing: negotiation}

Scholarly publishers do not need to require the author to transfer all his/her rights in order to publish the Work, but most of them do. ${ }^{5}$ The author instead does need to retain certain rights, such as the right to archive the Work in a repository, re-publish it in a collection, or share it for research or teaching purposes.

As defined in the Cambridge Dictionary, a contract is a legal document stating and explaining a formal agreement between two different people or groups (for full definition of the term contract see https://dictionary.cambridge.org/it/dictionary/english/contract). The term agreement means that a contract, to be defined as such, must be negotiable by both parties, author and publisher.

Moreover, the economic rights upon the Work can be individually exploited: the author - who retains all the rights before signing the contract - does not have to assign all of them to just one subject. ${ }^{6}$ The author can, and must, negotiate the transfer of these rights, guarantee himself/herself the possibility to reuse the Work in the future, and archive it in a repository.

In conclusion, if the authors do not want to have restrictions on sharing their Work, they should carefully read the conditions before signing the publishing contract and eventually negotiating them.

\section{Addendum to a publication agreement}

An addendum to a publication agreement is a supporting tool that might be helpful when negotiating a Copyright transfer agreement. An addendum is a form that modifies some clauses of the contract. The author shall reserve the right to reuse and archive his/her own Work through the addendum.

The Scholarly Publishing and Academic Resources Coalition (SPARC) has made a standard form that an author may use to add rights to any contract for his/her Work (for the pdf form see https://sparcopen.org/wp-content/uploads/2016/01/AccessReuse_Addendum.pdf). In the addendum, the rights the author(s) aims at retaining must be specified. Once completed, the addendum is sent to the publisher in attachment to the cover letter, where it is recommended to mention that an addendum has been added to the agreement.

A lack of knowledge in the field of copyright and management of rights connected to publication deserves attention. Authors routinely give away all their rights, as if those represented a burden instead of an opportunity. ${ }^{7}$
Obviously, institutions have an important role in copyright issues: first, they should make sure that the health professionals/researchers are well aware of the potential of proper copyright management. Second, institutions should take on the responsibility of intellectual property management: a solo author has insufficient bargaining power, but when supported by an institutional policy, the situation can be reversed. An increasing number of academic and health institutions nowadays offer legal support for publication: it is useful for negotiating an addendum to the publishing contract, and it is necessary to fully support open access policies as requested at the institutional level or by many research funding bodies. ${ }^{8}$

In addition to negotiation, another valuable tool for intellectual property management is the Open Access Publishing model and the grant of licenses.

\section{Open Access Publishers}

We have already investigated how traditional publishers think about copyright management. The scenario is different when considering Open Access (OA) Publishing. OA Publishing is a movement that promotes free access to scientific knowledge. OA encourages scientists, researchers, and scholars to disseminate their own Work, making them freely accessible to all the scientific communities ${ }^{9}$ in different ways. These are informally defined as Open Access Roads: Gold Road and Green Road. Gold OA journals make the articles they publish immediately and freely available. These journals often require payment to cover the so-called publication fees (this quote is defined as APC - Article Processing Charge). The APC is usually taken care of by the institution where the author works. Green $O A$ journals allow the author to self-archive his/her Work in open access repositories - institutional or thematic either at the time of publication or after an embargo period. This embargo period may vary, commonly from 6 to 12 months, during which it is not possible to archive or share the document because the publisher retains a sort of sole right. Based on the provisions of the publisher, the author may self-archive the preprint, postprint, or the final version of the paper. ${ }^{10,11}$ Faced with the novelty represented by native OA Journals and platforms and dealing with the opportunity offered by selfarchiving contents in preprint, disciplinary or institutional repositories, traditional publishers have offered a third way in-between fully OA Journals and subscription journals: the hybrid Open Access. Hybrid OA are subscription-based journals that allow authors to make individual contents gold open access immediately on payment of an APC..$^{12}$ Most of the journals from the leading scholarly publishers are nowadays hybrid. Otherwise, fully Open Access journals apply open licenses to all the Works they publish. 
The term license derives from the Latin word liceere, which means to allow, to permit. Thanks to these licenses, the author grants the user (the Publisher) permission to use his/her own Work. The author remains the owner of the Work, allowing the Publisher to utilize the Work in a specified way. The most used licenses in OA Publishing are the Creative Commons (CC). The Creative Commons Project is a six-license package created to help people share their creative and academic work [...] and build a more equitable, accessible, and innovative world (for full description see https://creativecommons.org/about/). The licenses allow the author to manage the openness of his/her own Work and always guarantee appropriate credit to the author himself/herself.

Differently from traditional contracts (Copyright transfer agreement) - where the author is invited to surrender all his/her economic rights upon the Work to the Publisher - the CC licenses preserve the creator's intellectual property. Through CC licenses, the author can manage and control the use made out of his/her Work and, at the same time, these licenses guarantee a wide diffusion making a reproduction, archiving, and reuse of the Work legal.

\section{Italian laws on copyright and intellectual property rights}

The current Italian legislative framework on copyright and Intellectual Properties is very old yet very articulate (for full list of Italian copyright laws see https://wipolex.wipo.int/en/legislation/results?countryOrgs $=I T \&$ subjectMatters $=11$ ). The Law protecting copyright, and other rights related to its exercise, dates back to 1941, Law No. 633/1941. ${ }^{13}$ It underwent many modifications and integrations in more than half a century, harmonizing with the European copyright framework. Changes and additions to the original Law are manifold: these reflect political, cultural, and, above all, economic and technological changes, as well as the issue of international treaties and agreements, which have taken place in the almost 80 years since the entry into force of Law. The above-mentioned Law
No. 663/1941 was last updated in 2019 with the changes made by Law No. 37/2019. ${ }^{14}$

Researchers and clinicians, who work or publish in Italy must, therefore, deal with complex national copyright legislation. This includes specific law articles on scientific and academic publications funded by national public bodies, Art. 4 Law No. 112/2013 ${ }^{15}$ and, for academics - or would-be -, recent decrees of the Italian Ministry of Research (2020). This latter refers to the mandatory open access re-publication or self-archiving of results (strongly linked with governmental Research evaluation processes and Italian Agency for Research Evaluation - ANVUR). For those who publish the results of research financed by international bodies, agencies, foundations, charities, and private subjects, it is also mandatory to respect the agreements and guidelines issued by funders regarding copyright issues.

Due to the traditional system of Authors' rights management in the scientific and academic publishing cycle, scholarly authors commonly transfer their exclusive rights to publishers in exchange for publication process management and the positioning of the contribution in an editorial product. The Copyright transfer system, common to international and Italian academic publishers, requires authors and co-authors to understand their rights and the constraints - or benefits - contained in the legislation itself. Authors should keep in mind that any publishing contract will be subject to the copyright law in force in the country where the publisher has its registered offices (Table 1).

The Italian Copyright Law No. 633/1941 protects literary, musical, scientific, and didactic works (Art. 2, Title I, Chapter I). The law also establishes that (Art. 19, Title I - Copyright Provisions, Chapter III, Section I) The exclusive rights provided by the previous articles are independent of each other. The exercise of one does not exclude the exclusive exercise of each of the other rights. ${ }^{13}$ This implies that economic exploitation rights are independent of each other: it is unnecessary to assign all rights to the publishers. In accordance with the Italian Law, copyright transfer is only an option, a choice made by an author. Several legal tools

Table 1. Italian Legislative Framework relevant to copyright in scholarly publishing.

\begin{tabular}{|c|c|c|c|c|}
\hline Law & Description & Note & Document type & Publishers \\
\hline Law No. 633/1941 & $\begin{array}{c}\text { The Italian Law } \\
\text { protecting copyright, } \\
\text { and other rights related } \\
\text { to its exercise }\end{array}$ & $\begin{array}{l}\text { Last modified by } \\
\text { Law No. } 37 / 2019\end{array}$ & $\begin{array}{c}\text { Journal article, } \\
\text { book chapter, book }\end{array}$ & Italy \\
\hline Law No. $112 / 2013$ & $\begin{array}{c}\text { Italian Law on } \\
\text { Open Access to public-funded } \\
\text { Research }\end{array}$ & $\begin{array}{c}\text { It is expressed in the } \\
\text { Art. No. } 4\end{array}$ & $\begin{array}{c}50 \%+\text { public-funded research } \\
\text { outputs, primary } \\
\text { as Journal article and, } \\
\text { secondary, book chapter, book }\end{array}$ & Worldwide \\
\hline
\end{tabular}


can be used by scholarly authors, editors, or translators: non-exclusive contracts, licenses, or publishing agreement addendum.

The Italian Law specifically deals with scholarly Open Access (OA) to scientific publications in Article 4 of Law No. 112/2013. ${ }^{15}$ This Law Article was converted with modifications to Legislative Decree 91/2013 'Urgent provisions for the protection, enhancement, and revitalization of cultural and tourism assets and activities', which can be summarized as follows:

- Autonomously, public funding bodies shall adopt measures to promote open access to scientific results (identified by the Law 112/2013 as articles published in scholarly Journals) of research financed with a minimum of $50 \%$ public resources. Clearly, the Law is addressed not only to funded subjects but also to Italian funders such as Ministry of University and Research, the Ministry of Cultural Heritages, Italian Charities or Foundations (i.e., Telethon).

- Open Access takes place: i) through publication by the publisher, at the time of the first publication, as native OA content; ii) through the non-profit republication in institutional or disciplinary electronic repositories with an 18-month embargo from the first publication of works in STM areas, and a 24-month embargo for humanities and social science areas.

There is no clear statement of which version is subject to re-publication in the repositories. The Italian Law is silent on this point. The author can legitimately assume that the only version that can be deposited in an OA repository - as requested by the Law - is the version defined in the publishers' policies for self-archiving. Commonly set by the vast majority of publishers, these policies regulate if Authors are permitted to self-archive the submitted (preprint) version of the Work, the accepted (peer-reviewed) or the Final version, also defining whether the open access publication of the content version can take place immediately or after an embargo period. ${ }^{16}$

- In order to optimize retrieval and use of cultural and scientific information, the Ministry of Cultural Heritage and Tourism and the Ministry of University and Research must adopt strategies for the unification of their respectively managed research output databases. The Italian Ministry of Health is not mentioned as a stakeholder in Law No. $112 / 2013$.

- Implementation of the Law must not charge new or greater costs to Italian public finances. The public institutions involved must provide support with human, instrumental, and financial resources available under current legislation.
As written, Law No. 112/2013 partially acknowledged EU Recommendation 2012/417 about reuse of public and publicly funded outputs: the maximum deadlines (18-24 months) for the embargo on Open Access re-publication of contents far exceed the parameters set by the 2012/417 Recommendation (6-12 months).

\section{Open Access - The case COVID-19}

Nowadays, a worldwide open-access publishing system is extremely necessary for well-organized scientific dissemination and a common scientific agenda, a useful approach to effectively face the challenges connected to a globalized world.

In 2020, the scientific discourse must deal with the coronavirus 2019 (COVID-19) outbreak and its global impact. Sharing in open access most of the scientific literature related to the severe acute respiratory syndrome-related coronavirus 2 (SARS-CoV-2) pandemic has been of fundamental importance: this practice could be the starting point to overcome the paywalls imposed by traditional scientific publishing. ${ }^{17}$

On several preprint platforms, such as bioRxiv and medRxiv, dozens of articles on SARS-CoV-2 are collected daily. ${ }^{18}$ The joint effort to share new knowledge on this topic is also proven by the publication of genomic and sequencing data of the virus on open access platforms, such as the Global Initiative on Sharing Avian Influenza Data (GISAID; https://www.gisaid. org/) or GenBank (https://www.ncbi.nlm.nih.gov/ sars-cov-2/).

The availability of accurate and reliable epidemiological, clinical, and laboratory data is essential for guiding public health decision-making at the beginning of an epidemic. ${ }^{19}$

Thanks to the British Wellcome Trust statement (for the full statement see https://wellcome.org/coronavirus-covid-19/open-data), different protocols, emergency guidelines, and publications related to COVID-19 from over 100 scientific journals and institutions have been made accessible, sharing the most relevant information with the World Health Organization (WHO).

Many big academic publishing companies, which are deeply linked with a paywall economic model, have made most of their available resources in open access or free access. This openness is undoubtedly temporary but it clearly reveals that an open publication model is possible and necessary to enable an unprecedented rapid global scientific response..$^{20}$ At the same time, temporary access is not Open Access, which is always freely available and linked with open licenses. ${ }^{21}$ The current crisis offers the opportunity to renew the over 100-year-old practice of scientific and academic publication in a better and more aware context. 


\section{Open Access - Pubmed Central and European Pubmed Central}

The National Library of Medicine's (NLM) website PubMed Central (PMC; https://www.ncbi.nlm. nih.gov/pmc/) and the mirror site European PMC (https://europepmc.org/) are open biomedical repositories, where most of U.S. National Institutes of Health (NIH) and UK Wellcome Trust funded research (but also by other donors such as Telethon) are archived, and where full-text results are openly and permanently available without a paywall, due to funders' open access publishing policies.

PMC and EU PMC full-text items are indexed and provided with the National Center for Biotechnology Information's (NCBI) structured metadata, medical ontologies, and identifiers. The goal of the PMC technical environment is to preserve, re-distribute, and re-publish the U.S. publicly funded Health and Life Sciences research works in an easy way, through a self-archiving repository findable via PubMed, where publishers are responsible to automatically submit a self-archiving compliant version of the published work. ${ }^{22}$ For scientific research granted by NIH or other PMC compliant funders, the sponsorship must be submitted in advance to a traditional or open access publisher, which publishes the final edited version of the Work.

\section{Protecting our intellectual capital}

We have so far analyzed different tools that protect intellectual property: careful reading of the copyright agreement, negotiating the clauses proposed by the publisher using the addendum form, choosing the Open Access Publishing option, either the gold or green road.

Finally, since the copyright subject is hard to understand and has many aspects to take into consideration, it is crucial to request the support of staff with specific skills, ${ }^{23}$ such as librarians and attorneys. These professional figures are always part of a research institute. We aim to underline that it is important to protect the intellectual property of one's Work, both for the author and the users. The application of the principles we mentioned means valorizing research through its dissemination, increasing its visibility, and potential impact. In the academic field, citations represent the unit of measure of the value of someone's research. ${ }^{24}$ Being the holder and owner of our Work allows us to show, distribute, and archive it, thus giving it more visibility. Many studies have shown that Open Access Publishing generates more citations and feeds the author's bibliometric index (such as $h$-index) and those of the article (such as citation index and Altmetrics), and determines an impact that can be concretely measured in the scien- tific community. This measurable impact is the socalled Open Access Impact Advantage. The dissemination of knowledge - that often derives from good management of the intellectual property - also determines an influence in the audience. Audience as the general public, citizens, and businesses: the communication of knowledge feeds economic growth and strengthens the public awareness of science.

The awareness of our own intellectual capital encourages the growth of more capital: we must protect and fuel the virtuous circle of knowledge.

\section{References}

1. Teixeira da Silva JA. Should copyright be transferred before a manuscript is accepted? Ann Transl Med 2017;5:415.

2. Al-Khatib A, Teixeira da Silva JA. What rights do authors have? Sci Eng Ethics 2017;23:947-9.

3. Pitts A. Guest Post: Think Sci-Hub is Just Downloading PDFs? Think Again [Internet]. The Scholarly Kitchen. 2018 [cited 2020 May 6]. Available from: https://scholarlykitchen.sspnet.org/2018/09/18/guest-post-think-scihub-is-just-downloading-pdfs-think-again/

4. SPARC. Big Deal Cancellation Tracking [Internet]. SPARC. [cited 2020 Oct 7]. Available from: https://sparcopen.org/our-work/big-deal-cancellation-tracking/

5. Charbonneau DH, McGlone J. Faculty experiences with the National Institutes of Health (NIH) public access policy, compliance issues, and copyright practices. J Med Libr Assoc JMLA 2013;101:21-5.

6. Aliprandi S. Capire il copyright: percorso guidato nel diritto d'autore. Milano: Ledizioni; 2012. 163 p.

7. Galimberti P. Contratti e licenze [Internet]. 2016 [cited 2020 Aug 26]. Available from: https://docplayer.it/ 22899478-Contratti-e-licenze-paola-galimberti.html

8. Piwowar H, Priem J, Larivière V, et al. The state of OA: a large-scale analysis of the prevalence and impact of Open Access articles. PeerJ 2018;6:e4375.

9. De Robbio A. L'Open Access in Italia. DigItalia 2006;1:31-44.

10. Berg JM, Bhalla N, Bourne PE, et al. Preprints for the life sciences. Science 2016;352:899-901.

11. Goben A, Akers KG. Sharing your work by self-archiving: encouragement from the Journal of the Medical Library Association. J Med Libr Assoc JMLA 2020; 108:1-4.

12. Poltronieri E, Bravo E, Camerini T, et al. Where on earth to publish? A sample survey comparing traditional and open access publishing in the oncological field. J Exp Clin Cancer Res 2013;32:4.

13. Gazzetta Ufficiale. Protezione del diritto d'autore e di altri diritti connessi al suo esercizio [Internet]. 633, Apr 22, 1941. Available from: https://www.gazzettaufficiale.it/eli/id/1941/07/16/041U0633/sg

14. Gazzetta Ufficiale. Disposizioni per l'adempimento degli obblighi derivanti dall'appartenenza dell'Italia all'Unione europea [Internet]. 37, May 3, 2019. Available from: https://www.gazzettaufficiale.it/eli/id/2019/05/11/19G000 $44 / \mathrm{sg}$ 
15. Gazzetta Ufficiale. Disposizioni urgenti per la tutela, la valorizzazione e il rilancio dei beni e delle attivita' culturali e del turismo [Internet]. 91, Aug 8, 2013. Available from: https://www.gazzettaufficiale.it/eli/id/2013/10/ 08/13A08109/sg

16. Keele BJ, Odell J. Managing digital rights in Open Access works. In: Digital rights management: the librarian's guide [Internet]. 2016th ed. USA: Rowman \& Littlefield; 2017 [cited 2020 Oct 7]. Available from: https://osf.io/qxpsz

17. Heymann DL. Data sharing and outbreaks: best practice exemplified. The Lancet 2020;395:469-70.

18. Majumder MS, Mandl KD. Early in the epidemic: impact of preprints on global discourse about COVID-19 transmissibility. Lancet Glob Health 2020;8:e627-30.

19. Xu B, Kraemer MUG, Xu B, et al. Open access epidemiological data from the COVID-19 outbreak. Lancet Infect Dis 2020;20:534.
20. SPARC Europe. COVID-19 and Open Science [Internet]. SPARC Europe. [cited 2020 May 6]. Available from: https://sparceurope.org/covid-19-and-open-science/

21. Coalition-s. Open Access lessons during Covid-19: No lockdown for research results! [Internet]. coalition-s. 2020. Available from: https://www.coalition-s.org/openaccess-lessons-during-covid-19-no-lockdown-for-research-results/

22. Fain JA. NIH Public Access Policy: How does information get uploaded to PubMed Central and by whom? Diabetes Educ 2015;41:267.

23. Fernández-Molina J-C, Martínez-Ávila D, Silva EG. University copyright/scholarly communication offices: Analysis of their services and staff profile. J Acad Librariansh 2020;46:102133.

24. Tennant JP, Waldner F, Jacques DC, et al. The academic, economic and societal impacts of Open Access: an evidence-based review. F1000Research 2016;5:632 